\title{
EFFECTS OF LEVOSIMENDAN ON CELLULAR METABOLIC ALTERATIONS IN PATIENTS WITH SEPTIC SHOCK: A RANDOMIZED CONTROLLED PILOT STUDY
}

\author{
Zied Hajjej, ${ }^{*}$ Bilel Meddeb, ${ }^{*}$ Walid Sellami, ${ }^{*}$ Iheb Labbene, ${ }^{*}$ \\ Andrea Morelli, ${ }^{\dagger}$ and Mustapha Ferjani ${ }^{*}$ \\ ${ }^{*}$ Department of Anesthesiology and Critical Care Medicine, Faculty of Medicine of Tunis, University of \\ Tunis El manar, Military Hospital of Tunis, Tunis, Tunisia; and ${ }^{\dagger}$ Department of Cardiovascular, \\ Respiratory, Nephrological, Anesthesiological and Geriatric Sciences, University of Rome, "La Sapienza," \\ Rome, Italy
}

Received 17 Nov 2016; first review completed 5 Dec 2016; accepted in final form 13 Feb 2017

\begin{abstract}
Introduction: Mitochondrial dysfunction and consequent cellular energetic failure play a key role in the development of sepsis-related organs failure. Evidence suggests that the pleiotropic effects of levosimendan may positively affect cellular metabolism during septic shock. Objectives: To investigate changes in the concentration of glucose, lactate, pyruvate, and glycerol in the extracellular fluid of the skeletal muscle following levosimendan administration in patients with septic shock. Methods: The study was designed as a prospective, double-blind, controlled, clinical pilot trial and performed in a multidisciplinary intensive care unit. After achieving normovolemia and a mean arterial pressure of at least $65 \mathrm{~mm} \mathrm{Hg}, 20$ septic shock patients were randomized to receive either levosimendan $0.2 \mu \mathrm{g} / \mathrm{kg} / \mathrm{min}(\mathrm{n}=10)$, or dobutamine $5 \mu \mathrm{g} / \mathrm{kg} / \mathrm{min}$ as active comparator $(n=10)$. Interstitial tissue concentrations of lactate, pyruvate, glucose, and glycerol were obtained by using muscle microdialysis. All measurements, including data from right heart catheterization, were obtained at baseline and every $6 \mathrm{~h}$ for the following $72 \mathrm{~h}$ after randomization. The trial is registered with Clinicaltrials.gov, number NCT02963454. Results: Compared with dobutamine, levosimendan increased interstitial tissue pyruvate concentration (153.3 \pm 73 and $187.2 \pm 13.5$ vs. $210.7 \pm 76.2$ and $161 \pm 64.6 ; P<0.05)$, and lactate clearance (55 vs. 10$)$. Lactate/pyruvate ratio was lower in the levosimendan group at the end of study period ( $37.7 \pm 18.9$ and $29.3 \pm 12.7$ vs. $10.9 \pm 4.5$ and $31.4 \pm 13.2 ; P<0.05$ ). Conclusion: Although we investigated a small number of patients, our preliminary results suggest that levosimendan may improve cellular metabolic alterations in patients with septic shock.
\end{abstract}

KEYWORDS—Levosimendan, metabolism, microcirculation, microdialysis, septic shock

\section{INTRODUCTION}

Cellular energetic failure often characterizes the progression of septic shock and is associated with increased mortality (1-4). The underlying mechanisms of such energetic failure are complex and involve several pathophysiological pathways including microvascular derangement and mitochondrial dysfunction (1-4). Reversing cellular energetic failure may represent an effective therapeutic target for improving outcome. Evidence suggests that levosimendan can be safely administered in patients with septic shock requiring inotropic support (5). However, when used to prevent organ dysfunction, levosimendan did not show outcome benefit (6). In addition to its inotropic and vasodilator effects, levosimendan (a calcium sensitizer), has anti-inflammatory, antiapoptotic and antioxidant effects (7). Furthermore, it may positively affect mitochondrial function by opening adenosine triphosphate (ATP)sensitive potassium $\left(\mathrm{K}_{\mathrm{ATP}}\right)$ channels $(7)$. Due to these

Address reprint requests to Zied Hajjej, Ph, Department of Anesthesiology and Critical Care Medicine, Faculty of Medicine of Tunis, University of Tunis El manar, Military Hospital of Tunis, LR12DN01, 1008 Montfleury, Tunis, Tunisia.

E-mail: hajjej_zied@hotmail.com

The authors report no conflicts of interest.

DOI: $10.1097 /$ SHK.0000000000000851

Copyright (C) 2017 The Author(s). Published by Wolters Kluwer Health, Inc. on behalf of the Shock Society. This is an open access article distributed under the terms of the Creative Commons Attribution-Non Commercial-No Derivatives License 4.0 (CCBY-NC-ND), where it is permissible to download and share the work provided it is properly cited. The work cannot be changed in any way or used commercially without permission from the journal. pleiotropic properties, levosimendan may potentially improve cellular metabolism. Nevertheless, the effects of this drug on cellular metabolic activity in septic shock are not fully elucidated. Microdialysis allows the analysis of the interstitial fluid concentrations of glucose, lactate, pyruvate, and glycerol which reflect the energy metabolism of the cells $(8,9)$. Indeed, it is widely accepted that lactate/pyruvate ratio ( $\mathrm{L} / \mathrm{P}$ ratio) is a marker of the adequacy of oxygen delivery to tissues oxygen demand and correlates with clinical outcome $(8,9)$. Microdialysis may thus be used to accurately detect the efficacy of pharmacological interventions in improving cellular metabolism. The aim of the present randomized, double-blind, controlled pilot study was therefore to investigate the effects of levosimendan on cellular metabolism in patients with septic shock, by using muscle microdialysis. We hypothesized that levosimendan improves interstitial $\mathrm{L} / \mathrm{P}$ ratio and lactate clearance.

\section{PATIENTS AND METHODS}

\section{Patients}

After the approval by the Institutional Ethics Authorities, the study was performed in the intensive care unit of the Tunis Military Hospital and registered in Clinicaltrials.gov as NCT02963454. Written informed consent was obtained from the patients' next of kin or from the legally authorized representatives. Enrolment of patients started in August 2011 and ended in May 2014. We enrolled patients who fulfilled the criteria of septic shock requiring norepinephrine (NE) to maintain a mean arterial pressure (MAP) of at least $65 \mathrm{~mm} \mathrm{Hg}$ despite appropriate volume resuscitation (pulmonary 
arterial occlusion pressure [PAOP] $=12 \mathrm{~mm} \mathrm{Hg}$ to $18 \mathrm{~mm} \mathrm{Hg}$ and central venous pressure $[\mathrm{CVP}]=8 \mathrm{~mm} \mathrm{Hg}$ to $12 \mathrm{~mm} \mathrm{Hg}$ ) (10). Septic shock criteria were defined according to current Surviving Sepsis Campaign guidelines (10) which include the presence of sepsis-related refractory hypotension (MAP $<$ $65 \mathrm{~mm} \mathrm{Hg}$ ) unresponsive to fluid challenge $(20 \mathrm{~mL} / \mathrm{kg}-40 \mathrm{~mL} / \mathrm{kg})$. Exclusion criteria were pregnancy, uncontrolled hemorrhage, terminal heart failure, significant valvular heart disease, documented or suspected acute coronary syndrome, and limitations on the use of inotropes: left ventricle outflow obstruction, systolic anterior motion of the mitral valve.

\section{Systemic hemodynamics, global oxygen transport, and acid-base homeostasis}

Systemic hemodynamic monitoring of the patients included a pulmonary artery catheter (7.5-F; Edwards Lifesciences, Irvine, Calif) and a radial artery catheter. MAP, CVP, mean pulmonary arterial pressure, and PAOP were measured at end-expiration. Heart rate was analyzed from a continuous recording of electrocardiogram with ST segments monitored. Cardiac index was measured using the continuous thermodilution technique (Vigilance II; Edwards Lifesciences). Oxygen delivery index $\left(\mathrm{DO}_{2} \mathrm{I}\right)$, oxygen consumption index, and oxygen extraction ratio were calculated by means of standard formulae.

Arterial and mixed-venous blood samples were collected to determine oxygen tensions and saturations as well as carbon dioxide tensions, standard bicarbonate, $\mathrm{pH}$, lactate concentrations, glucose, and hemoglobin.

\section{Microdialysis variables}

Muscle microdialysis was performed using a microdialysis probe (CMA 60, $\mathrm{CMA}$ /microdialysis, Stockholm, Sweden) inserted into the quadriceps femoris muscle and connected to a microinjection pump (CMA 107, CMA microdialysis $\mathrm{AB}$, Solna, Sweden) at $0.3 \mu \mathrm{L} / \mathrm{min}$ of perfusion flow rate of ringer solution without lactate $(8,11,12)$. The sampling of the dialysate liquid was started after a $2 \mathrm{~h}$ equilibration period (13). Microvial tubes for collecting samples of the interstitial fluid were collected concomitantly with the hemodynamic evaluation. The interstitial tissue concentrations of lactate, pyruvate, glucose, and glycerol were analyzed by using a CMA 600 Analyser (CMA 600 Microdialysis Analyser; CMA Microdialysis AB). The L/P ratio was calculated automatically by the machine. As previously described (14), both blood and muscle lactate clearance were defined by the equation: [(lactate baseline $^{-}$lactate delayed $_{\text {) }}$ lactate baseline $] \times 100 \%$. Lactate delayed are blood lactate concentrations measured at 12 , 24,48 , and $72 \mathrm{~h}$. Positive values indicate a decrease or clearance of lactate (14).

\section{Study design}

Twenty patients were randomly allocated to the treatment with either intravenous levosimendan $0.2 \mu \mathrm{g} / \mathrm{kg}$ per minute (without a loading bolus dose) for $24 \mathrm{~h}$ or intravenous dobutamine $5 \mu \mathrm{g} / \mathrm{kg}$ per minute as active comparator, in a double-blinded manner (each $\mathrm{n}=10$ ). Dobutamine were administered during all the $72 \mathrm{~h}$ study period. During the study period, conventional treatment was continued as per usual practice. Fluid challenges were performed, and repeated as necessary, to maintain CVP $\geq 8 \mathrm{~mm} \mathrm{Hg}$ and PAOP $\geq 12 \mathrm{~mm} \mathrm{Hg} \mathrm{(10).} \mathrm{NE} \mathrm{was}$ titrated to maintain MAP $\geq 65 \mathrm{~mm} \mathrm{Hg}$. Packed red blood cells were transfused when $\mathrm{Hb}$ concentrations decreased below $7 \mathrm{~g} / \mathrm{dL}$, or if the patient exhibited clinical signs of inadequate systemic oxygen supply (10). All patients were sedated with remifentanil and midazolam and received mechanical ventilation using a volume-controlled mode. All measurements including systemic hemodynamic variables, acid-base variables blood gases, and glucose as well as interstitial tissue concentrations of lactate, pyruvate, glucose, and glycerol were determined at baseline and then every $6 \mathrm{~h}$ for the following $72 \mathrm{~h}$ after randomization.

\section{Statistical analysis}

Statistical analysis was performed by using SPSS v.20.0 (IBM Corp, Armonk, NY) software for statistical analysis. Baseline and demographic data were compared with a Mann-Whitney rank sum test or chi-square test, as appropriate. Microvascular and hemodynamic variables were analyzed with a Mann-Whitney rank sum test. Data are expressed as median (25th; 75th percentile), if not otherwise specified. Correlations between arterial and interstitial lactate and glucose concentrations within each group were analyzed by Spearman rank order correlation. A $P$ value $<0.05$ was considered statistically significant. As a pilot study, our aim was to provide preliminary data to test the hypothesis that levosimendan may affect cellular metabolic alterations in patients suffering from septic shock. Due to the lack of clinical data, the analyses performed in the present study were mandatory

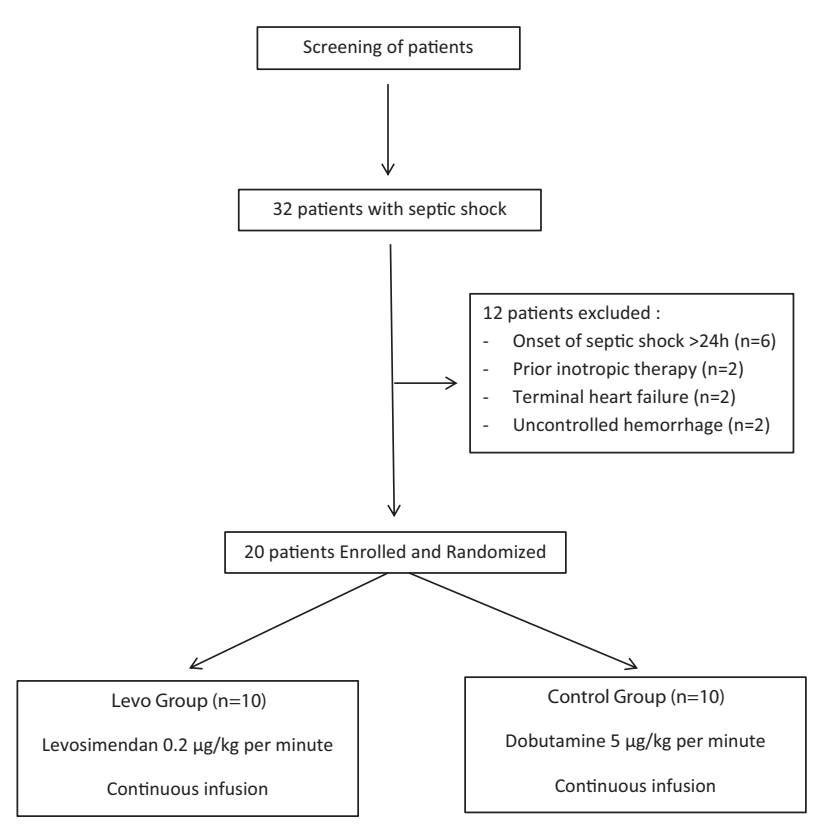

FIG. 1. Study flow chart.

exploratory and no ex ante power analysis was performed. Nevertheless, $a$ posteriori calculation, based on the primary results of the study, indicates that a sample size of eight subjects per group would have $80 \%$ power to detect a difference of 5\% between groups using a paired $t$ test at the $95 \%$ significance level.

\section{RESULTS}

\section{Demographic data}

Thirty-two patients with septic shock were screened and 20 patients were included in the study (Fig. 1). Demographic characteristics including age, gender, medical history, site of infection, Simplified Acute Physiology Score II score, and mortality were not different among groups (Table 1).

\section{Systemic hemodynamics, oxygen transport variables, acid-base homeostasis, and blood glucose}

Systemic hemodynamic variables, NE requirements, fluids administered, blood glucose, and acid-base homeostasis were

TABLE 1. Demographic characteristics of the investigated patients

\begin{tabular}{lccc}
\hline & $\begin{array}{c}\text { Control } \\
(\mathrm{n}=10)\end{array}$ & $\begin{array}{c}\text { Levosimendan } \\
(\mathrm{n}=10)\end{array}$ & $P$ \\
\hline Age, years & $61[24-69]$ & $51[36-62]$ & 0.469 \\
Males (n) & 9 & 8 & 0.535 \\
SAPS II & $51[48-68]$ & $57[44-68]$ & 0.305 \\
Comorbidities (n) & & & \\
$\quad$ Diabetes mellitus & 4 & 3 & 0.861 \\
$\quad$ Dyslipidemia & 3 & 1 & 0.475 \\
$\quad$ Hypertension & 5 & 3 & 0.563 \\
Sepsis sites (n) & & & \\
$\quad$ Pulmonary & 5 & 4 & \\
$\quad$ Abdominal & 2 & 1 & 0.562 \\
$\quad$ Central venous catheter & 1 & 1 & \\
$\quad$ Endocarditis & 1 & 1 & 0.608 \\
$\quad$ More than two sites & 1 & 3 & \\
Mortality (\%) & 50 & 30 & \\
\hline
\end{tabular}

Data are presented as median [25th; 75th percentile] or percentage. SAPS II indicates simplified acute physiology score. 
TABLE 2. Hemodynamic variables

\begin{tabular}{|c|c|c|c|c|c|}
\hline Variables & Groups & Baseline & $24 \mathrm{~h}$ & $48 \mathrm{~h}$ & $72 \mathrm{~h}$ \\
\hline \multirow[t]{2}{*}{ Heart rate (bpm) } & Control & 92 [84-102] & $101[90-112]$ & 105 [92-121] & 94 [82-108] \\
\hline & Levo & 102 [80-110] & 108 [90-116] & 108 [82-118] & 103 [81-112] \\
\hline \multirow[t]{2}{*}{ MAP $(\mathrm{mm} \mathrm{Hg})$} & Control & 73 [62-86] & 80 [68-91] & 78 [67-85] & 73 [60-87] \\
\hline & Levo & $74[60-84]$ & 77 [65-91] & 77 [60-88] & $81[74-94]$ \\
\hline \multirow[t]{2}{*}{$\mathrm{Cl}\left(1 / \mathrm{min} / \mathrm{m}^{2}\right)$} & Control & $3.5[3.2-4.4]$ & $4.1[3.7-4.9]$ & $4.2[3.8-5.1]$ & $4[3.1-4.9]$ \\
\hline & Levo & $4[3-4.6]$ & $4.5[3.6-5.2]$ & $4.4[3.8-5.4]$ & $4.7[3.9-5.2]$ \\
\hline \multirow[t]{2}{*}{ CVP (mm Hg) } & Control & $10.2[9-11.1]$ & $9.2[8.1-11.3]$ & $10.5[9-12.2]$ & $10[8.9-12.1]$ \\
\hline & Levo & $9.5[8.2-10.9]$ & $10.3[9-12.1]$ & $12.1[10-13.4]$ & $11[10.3-12.4]$ \\
\hline \multirow[t]{2}{*}{$\mathrm{DO}_{2} \mathrm{I}\left(\mathrm{ml} / \mathrm{min} / \mathrm{m}^{2}\right)$} & Control & 452 [387-532] & 539 [402-631] & 623.9 [567-730] & $538.8[497-602]$ \\
\hline & Levo & $546[497-646]$ & 594 [477-652] & 588 [497-629] & 611 [507-694] \\
\hline \multirow[t]{2}{*}{$\mathrm{VO}_{2} \mathrm{I}\left(\mathrm{mL} / \mathrm{min} / \mathrm{m}^{2}\right)$} & Control & $143[87-212]$ & 156 [94-282] & 161 [94-302] & $149[76-227]$ \\
\hline & Levo & $151[71-231]$ & 167 [80-272] & $159[77-287]$ & $141[81-294]$ \\
\hline \multirow[t]{2}{*}{$\mathrm{O}_{2}$-ER (\%) } & Control & 26 [20-34] & 25 [20-32] & 26 [21-35] & 28 [21-37] \\
\hline & Levo & 24 [19-32] & 27[22-33] & 25 [19-38] & $26[18-36]$ \\
\hline \multirow[t]{2}{*}{ NE Dose $(\mu \mathrm{g} / \mathrm{kg} / \mathrm{min})$} & Control & $0.2[0.1-0.7]$ & $0.27[0.1-0.6]$ & $0.25[0.1-0.8]$ & $0.29[0.08-0.9]$ \\
\hline & Levo & $0.3[0.1-0.8]$ & $0.34[0.2-0.9]$ & $0.31[0.18-1.1]$ & $0.29[0.1-1]$ \\
\hline \multirow[t]{2}{*}{ Glycemia (mmol/L) } & Control & $12[11.1-12.8]$ & $10.3[9-11.8]$ & $10.8[9.1-12.9]$ & $10.1[9.2-11.8]$ \\
\hline & Levo & $10.7[9.1-12.4]$ & $11.8[10.1-12.9]$ & $10.4[8.9-12.4]$ & $9.7[8.7-10.9]$ \\
\hline \multirow[t]{2}{*}{ Fluid input, $\mathrm{mL} / 24 \mathrm{~h}$} & Control & $1,010[902-1,220]$ & $898[778-1,120]$ & 895 [778-1,129] & $890[778-1,001]$ \\
\hline & Levo & $1,185[1,078-1,328]$ & $997[842-1,200]$ & $912[808-1,190]$ & $909[838-1,124]$ \\
\hline
\end{tabular}

Data are presented as median [25th; 75th percentile]. No statistically significant differences were found in any of the investigated variables. $\mathrm{Cl}$ indicates cardiac index; CVP, central venous pressure; $\mathrm{DO}_{2}$ l, systemic oxygen delivery index; MAP, mean arterial pressure; NE, norepinephrine; $\mathrm{O} 2-\mathrm{ER}$, oxygen extraction ratio; $\mathrm{VO}_{2} \mathrm{l}$, oxygen consumption index.

comparable between groups at baseline and at any different collection time points (Tables 2 and 3).

\section{Microdialysis variables}

At baseline, the interstitial tissue concentrations of lactate, pyruvate, glucose, glycerol, as well as L/P ratio did not differ between groups. However, at the end of the study period we noticed a significant decrease in the muscle $\mathrm{L} / \mathrm{P}$ ratio in the levosimendan group when compared with the dobutamine group (28.4 [20.4-45.5] vs. 10.1 [6.9-14.4] respectively; $P<0.05$ ) (Fig. 2). In addition, lactate clearance (55 vs. 10) and pyruvate concentration were higher in the levosimendan group at the end of the study period (215.7 [138-284] vs. 114 [73-199] respectively, all $P<0.05$ ) (Fig. 2). Muscle lactate tended to be lower in the levosimendan group at the end of the study period. However, this difference did not reach statistical significance $(P=0.05)$. No statistically significant differences were found in the other investigated variables.

Negative weak correlations were found between $\mathrm{DO}_{2} \mathrm{I}$ and muscle lactate $(\mathrm{rho}=-0.234, P<0.001), \mathrm{L} / \mathrm{P}$ ratio $(\mathrm{rho}=$ $-0.142, P=0.021$ ), and muscle glucose $($ rho $=-0.309$, $P<0.001)$.

A significant positive correlation existed between muscle and blood lactate concentrations and between muscle and blood glucose concentrations.

\section{DISCUSSION}

This pilot study was the first to evaluate changes in the concentrations of glucose, lactate, pyruvate, and glycerol in the

TABLE 3. Oxygenation profile and acid-base homeostasis

\begin{tabular}{|c|c|c|c|c|c|}
\hline Variables & Groups & Baseline & $24 \mathrm{~h}$ & $48 \mathrm{~h}$ & $72 \mathrm{~h}$ \\
\hline \multirow[t]{2}{*}{$\mathrm{pH}$} & Control & $7.4[7.38-7.42]$ & $7.38[7.36-7.40]$ & 7.39 [7.37-7.44] & $7.42[7.38-7.45]$ \\
\hline & Levo & $7.4[7.38-7.44]$ & $7.41[7.39-7.43]$ & 7.4 [7.37-7.43] & $7.5[7.39-7.52]$ \\
\hline \multirow[t]{2}{*}{$\mathrm{PaO}_{2}(\mathrm{~mm} \mathrm{Hg})$} & Control & $135[124-142]$ & 142 [129-149] & $128[117-132]$ & $123[114-138]$ \\
\hline & Levo & $129[109-134]$ & $125[108-133]$ & $121[111-140]$ & $118[101-131]$ \\
\hline \multirow[t]{2}{*}{$\mathrm{PaO}_{2} / \mathrm{FiO}_{2}$} & Control & 265 [198-301] & 342 [291-410] & $291[194-360]$ & 289 [201-361] \\
\hline & Levo & $235.6[190-321]$ & 283 [201-381] & $259[165-374]$ & 278 [199-387] \\
\hline \multirow[t]{2}{*}{$\mathrm{PaCO}_{2}(\mathrm{~mm} \mathrm{Hg})$} & Control & $39[33-42]$ & $43[39-45]$ & $36[33-41]$ & $34[30-41]$ \\
\hline & Levo & $42[38-46]$ & 38 [33-42] & 39 [34-45] & $34[29-40]$ \\
\hline \multirow[t]{2}{*}{$\mathrm{HCO}_{3}{ }^{-}(\mathrm{mmol} / \mathrm{L})$} & Control & $24[22-30]$ & 29 [24-33] & 27 [23-32] & $28[26-34]$ \\
\hline & Levo & $25[23-31]$ & $28[21-34]$ & $30[23-36]$ & $31[25-38]$ \\
\hline \multirow[t]{2}{*}{$\mathrm{SaO}_{2}(\%)$} & Control & 98 [96-99] & 96 [94-98] & 97 [95-99] & 97 [95-99] \\
\hline & Levo & 97 [95-99] & 97 [95-99] & 96 [94-99] & 96 [94-99] \\
\hline \multirow[t]{2}{*}{ Blood lactate (mmol/L) } & Control & $1.7[1.4-2.2]$ & $1.9[1.5-2.4]$ & $1.2[1-2]$ & $1.6[1.3-1.9]$ \\
\hline & Levo & $2.1[1.7-2.8]$ & $2.2[1.8-2.5]$ & $2[1.4-2.2]$ & $1.4[1-2.4]$ \\
\hline \multirow[t]{2}{*}{ Hemoglobin (g/dL) } & Control & $9.9[8.7-10.4]$ & $9.7[8.8-10.6]$ & 9 [8.1-10.2] & $9.1[8.6-10.7]$ \\
\hline & Levo & $10.8[8.6-10.3]$ & $10.1[9.1-10.9]$ & $9.4[8.8-10.4]$ & $9.8[9-10.9]$ \\
\hline
\end{tabular}

Data are presented as median [25th; 75th percentile]. No statistically significant differences were found in any of the investigated variables.

$\mathrm{FiO}_{2}$ indicates fractional inspired of oxygen; $\mathrm{HCO}_{3}$, bicarbonate; $\mathrm{PaCO}_{2}$, arterial partial pressure of carbon dioxide; $\mathrm{PaO}_{2}$, arterial partial pressure of oxygen; $\mathrm{pH}$, potentia hydrogenii; $\mathrm{SaO}_{2}$, arterial oxygen saturation. 

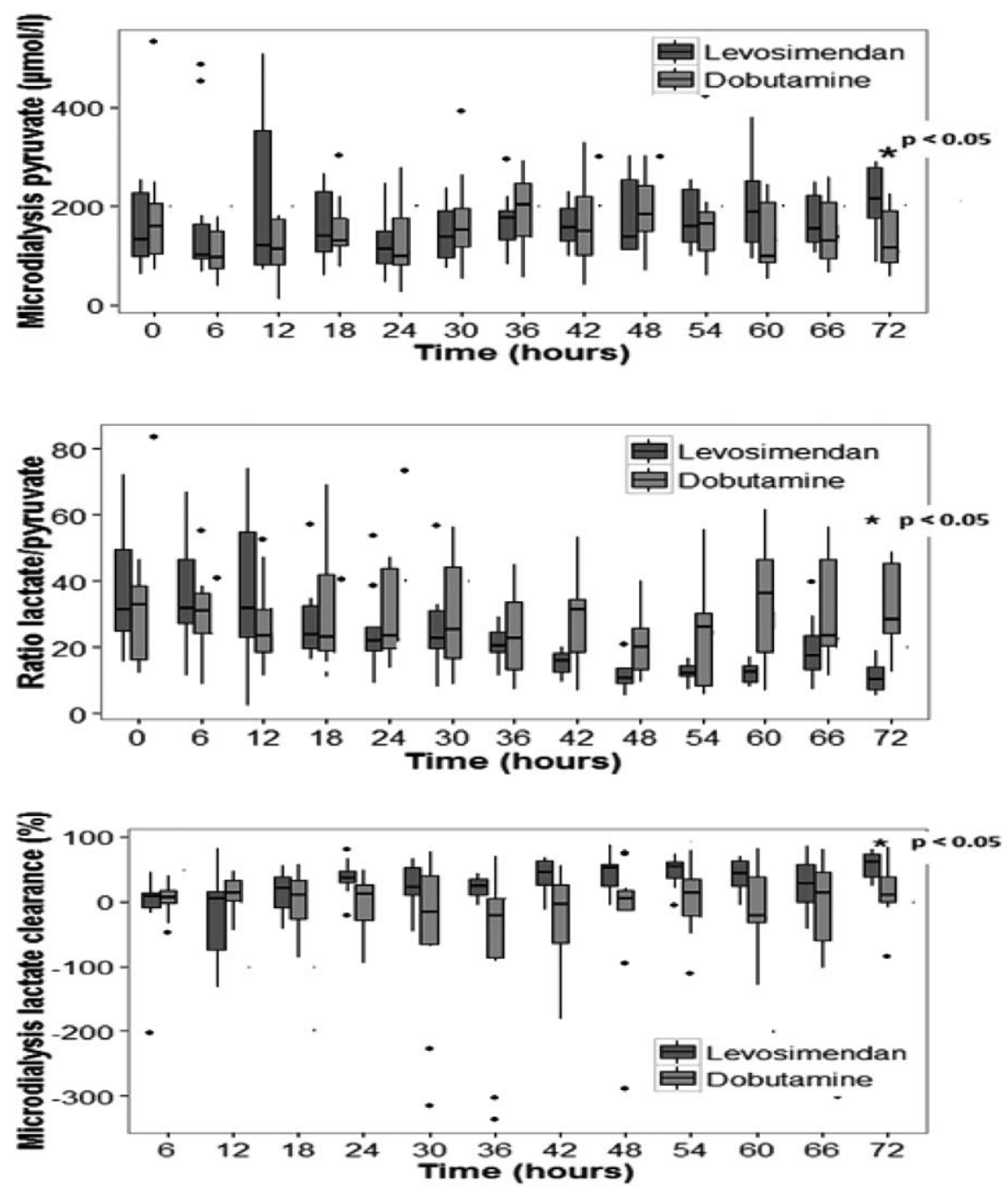

FIG. 2. Evolution of muscle pyruvate, lactate /pyruvate ratio, and lactate clearance between groups. ${ }^{\star} P<0.05$ between groups at $72 \mathrm{~h}$.

extracellular fluid of the skeletal muscle during levosimendan administration in patients with septic shock. The major finding of the present study is that levosimendan improved cellular energy metabolism, as indicated by reduced $\mathrm{L} / \mathrm{P}$ ratio and both increased lactate clearance and pyruvate concentration. Of note, such improvement was not related to changes in systemic hemodynamics.

Interstitial L/P ratio is influenced by the cellular switching from aerobic to anaerobic energy metabolism and thus indicates the presence of tissue local oxygen delivery and consumption mismatching $(9,12,13)$. Indeed, a decreased oxygen and glucose cellular availability leads to anaerobic energy metabolism with increased lactate and reduced pyruvate concentrations as pyruvate is metabolized to lactate. As a consequence, under hypoxic conditions $\mathrm{L} / \mathrm{P}$ ratio increases $(9,12,13)$. Changes in L/P ratio may therefore accurately indicate a condition of tissue hypoxia and/or ischemia, and it is wide accepted that a ratio $>25$ indicates the onset of anaerobic metabolism $(9,14)$. Nevertheless, an increased L/P ratio in the presence of elevated pyruvate may be the consequence not only of decreased oxygen delivery (ischemic hypoxia) but also of mitochondrial dysfunction $(9,15)$.
In the present study, we found elevated baseline values of L/P ratio and pyruvate in both dobutamine and levosimendan groups. These findings indicate that despite the achievement of adequate hemodynamic optimization, our patients suffered from a condition of emerging cellular energetic failure.

Levosimendan is a calcium-sensitizing drug and exerts its inotropic effect principally via binding to the calcium-saturated troponin $\mathrm{C}$ of myocardial thin filament. This action results in stabilization of the calcium-bound conformation of troponin, thereby prolonging the actin-myosin interaction without altering cross-bridge cycling. In addition, levosimendan exerts vasodilatory properties via the activation of ATP-dependent potassium channels $\left(\mathrm{K}_{\mathrm{ATP}}\right)(5-8)$.

In patients with septic myocardial dysfunction levosimendan improves myocardial performance (16-18), exerts anti-inflammatory effects, and decreases iNOS expression and activity, as well as NF-kB-dependent transcription $(7,19)$. Furthermore, levosimendan improves both endothelial function and the endothelium-dependent flow-mediated dilatation (7). By opening the $\mathrm{K}_{\mathrm{ATP}}$ channel located at the level of mitochondria, levosimendan may also preserve cellular energy homeostasis and protect mitochondria from oxidative stress $(7,19-21)$. 
Taken together, all these findings suggest that the pleiotropic effects of levosimendan may positively affect sepsis-induced cellular metabolic alterations. In fact, we observed that levosimendan attenuated cellular energetic failure as indicated by reduced $\mathrm{L} / \mathrm{P}$ ratio at the end of study period. The reduction in $\mathrm{L} / \mathrm{P}$ ratio indicates that the improvement in energy metabolism was due to increased cellular oxygen availability. This assumption is strengthened by the parallel increase in pyruvate concentration following levosimendan administration. Such an increase can be explained with the recovery of aerobic metabolism which led to accelerated cellular uptake and conversion of lactate into pyruvate by lactate dehydrogenase for increased oxidation (22).

At the level of microcirculation, sepsis induces a reduction of the perfused vessel density, leading to augmented intercapillary distances. As a result, the oxygen diffusion distance increases and may exceed the critical threshold (the maximum distance from oxygen source that allows the maintenance of mitochondrial efficiency).

Thanks to its vasodilatory and pleiotropic effects, levosimendan enhances both convection and diffusion (increased perfused vessel density), thereby reducing oxygen diffusion distance. This in turn increases microvascular oxygen delivery and cellular oxygen availability $(23,24)$.

We cannot exclude that a better mitochondrial performance contributed to such improvement. In this regard, it has been shown that levosimendan did not affect the activity of the respiratory chain complexes I, II, and III in a small series of septic shock patients (22). However, levosimendan, by opening mitochondrial $\mathrm{K}_{\mathrm{ATP}}$ channels, had the ability to protect mitochondria from the excessive production of reactive oxygen species, such as superoxide, peroxynitrite, and nitric oxide and this ability may potentially mitigate the bioenergetic failure (7, 21, 22). From a pathophysiological point of view, an improvement in microvascular blood flow precedes the recovery of the cellular metabolic alterations and thus the reversal of bioenergetic failure. This may explain why we observed improved cellular metabolism after $72 \mathrm{~h}$ from levosimendan administration. However, the present study design did not allow us to assess the time frame relationships between changes in cellular metabolism and microvascular blood flow, as investigating the latter requires different monitoring techniques (25).

In accordance with the previous study (24), our protocol required the administration of $5 \mu \mathrm{g} \cdot \mathrm{kg}^{-1} \cdot \mathrm{min}^{-1}$ dobutamine as an active comparator and such dobutamine dose did not affect neither systemic hemodynamics nor microdialysis variables. In this regard studies on the effects of dobutamine on microcirculation show conflicting findings. De Backer et al. (26) demonstrated that dobutamine at the dose of $5 \mu \mathrm{g} \cdot \mathrm{kg}^{-1}$. $\min ^{-1}$ improved but failed to normalize capillary blood flow in patients with septic shock. By contrast, in a more recent study, the administration of similar dobutamine dose failed to improve microcirculation (27). Adrenergic receptor and signaling abnormalities that typically occur during septic shock may account for the heterogeneous response of microcirculation following dobutamine administration.

The present study has some limitations that we would like to acknowledge. First, due to limited human and economic resources the number of investigated patients was small. However, the sample size was similar to previous experimental and clinical studies with the respective methodology (28-31) and the consistency of the cellular metabolic response to levosimendan was evident. Second, owing to the lack of investigation of specific mitochondrial variables such as the activities of the respiratory chain complexes, we cannot conclude whether improved mitochondrial function has contributed to the observed changes in cellular energy metabolism. Third, we investigated the changes in the metabolism of the muscle cells which might not be representative of the cells in other tissues. Fourth, in accordance with the previous study (24), we used a low dose of dobutamine as an "active comparator" to facilitate blinding of the study drugs as levosimendan may induce evident hemodynamic changes. Because the aim of our study was not to perform a direct comparison between the two drugs, a critical discussion on the effect of dobutamine is outside the scope of the present study. Fifth, patients receiving levosimendan were younger (although not significantly different), therefore we cannot exclude age-related different effects of the study drug. Nevertheless, systemic hemodynamic and acid-base homeostasis did not differ between the two study groups. Finally, our study protocol required a $72 \mathrm{~h}$ observational period. Such a study design does not allow excluding a direct timedependent effect unrelated to the specific agent.

\section{CONCLUSION}

This is the first prospective, randomized clinical study investigating the effects of levosimendan on cellular metabolism in septic shock patients by analyzing the concentrations of glucose, lactate, pyruvate, and glycerol in the extracellular fluid of the skeletal muscle. Although we investigated a small number of patients, our results demonstrate that levosimendan at $0.2 \mu \mathrm{g} / \mathrm{kg}$ per minute improves muscle cellular energy metabolism in volume-resuscitated septic shock patients. Such improvement was mainly the consequence of increased oxygen delivery at the level of microcirculation as it was not associated with changes in systemic hemodynamic. These results need to be confirmed in a larger trial.

\section{ACKNOWLEDGMENTS}

The authors show their gratitude to doctors and nurses with the Intensive Care Unit who provided care for the patients included in the study.

\section{REFERENCES}

1. Angus DC, van der Poll T: Severe sepsis and septic shock. $N$ Engl J Med 369(9):840-851, 2013.

2. Angus DC, Linde-Zwirble WT, Lidicker J, Clermont G, Carcillo J, Pinsky MR: Epidemiology of severe sepsis in the United States: analysis of incidence, outcome, and associated costs of care. Crit Care Med 29(7):1303-1310, 2001.

3. Goldenberg NM, Steinberg BE, Slutsky AS, Lee WL: Broken barriers: a new take on sepsis pathogenesis. Sci Transl Med 3(88):88s25, 2011.

4. Trzeciak S, McCoy JV, Phillip Dellinger R, Arnold RC, Rizzuto M, Abate NL: Early increases in microcirculatory perfusion during protocol-directed resuscitation are associated with reduced multi-organ failure at $24 \mathrm{~h}$ in patients with sepsis. Intensive Care Med 34(12):2210-2217, 2008.

5. Zangrillo A, Putzu A, Monaco F, Oriani A, Frau G, De Luca M, Di Tomasso N, Bignami E, Lomivorotov V, Likhvantsev V, et al.: Levosimendan reduces mortality in patients with severe sepsis and septic shock: a meta-analysis of randomized trials. J Crit Care 30(5):908-913, 2015. 
6. Gordon AC, Perkins GD, Singer M: Levosimendan for the prevention of acute organ dysfunction in sepsis. N Engl J Med 375(17):1638-1648, 2016.

7. Farmakis D, Alvarez J, Gal TB, Brito D, Fedele F, Fonseca C, Gordon AC, Gotsman I, Grossini E, Guarracino F, et al.: Levosimendan beyond inotropy and acute heart failure: evidence of pleiotropic effects on the heart and other organs: an expert panel position paper. Int J Cardiol 222:303-312, 2016.

8. Ungerstedt U: Microdialysis - principles and applications for studies in animals and man. J Intern Med 230(4):365-373, 1991.

9. Nikitas N, Kopterides P, Ilias I, Theodorakopoulou M, Vassiliadi DA, Armaganidis A: Elevated adipose tissue lactate to pyruvate $(\mathrm{L} / \mathrm{P})$ ratio predicts poor outcome in critically ill patients with septic shock: a microdialysis study. Minerva Anestesiol 79(11):1229-1237, 2013.

10. Dellinger RP, Levy MM, Rhodes A, Annane D, Gerlach H, Opal SM, Sevransky JE, Sprung CL, Douglas IS, Jaeschke R, et al.: Surviving sepsis campaign: international guidelines for management of severe sepsis and septic shock: 2012. Crit Care Med 41(2):580-637, 2013.

11. Farnebo S, Samuelsson A, Henriksson J, Karlander L-E, Sjöberg F: Urea clearance: a new method to register local changes in blood flow in rat skeletal muscle based on microdialysis. Clin Physiol Funct Imaging 30(1):57-63, 2010.

12. Levy B, Perez P, Gibot S, Gerard A: Increased muscle-to-serum lactate gradient predicts progression towards septic shock in septic patients. Intensive Care Med 36(10):1703-1709, 2010.

13. Ungerstedt U, Rostami E: Microdialysis in neurointensive care. Curr Pharm 10(18):2145-2152, 2004.

14. Marty P, Roquilly A, Vallée F, Luzi A, Ferré F, Fourcade O: Lactate clearance for death prediction in severe sepsis or septic shock patients during the first 24 hours in Intensive Care Unit: an observational study. Ann Intensive Care 3(1):3-7, 2013.

15. Waelgaard L, Dahl BM, Kvarstein G, Tonnessen T: Tissue gas tension and tissue metabolites for detection of organ hypoperfusion and ischemia. Acta Anaesthesiol Scand; 2012;(2):200-209, 2012.

16. Morelli A, De Castro S, Teboul J-L, Singer M, Rocco M, Conti G: Effects of levosimendan on systemic and regional hemodynamics in septic myocardial depression. Intensive Care Med 31(5):638-644, 2005.

17. Memiş D, Inal MT, Sut N: The effects of levosimendan vs dobutamine added to dopamine on liver functions assessed with noninvasive liver function monitoring in patients with septic shock. J Crit Care 27(3):318.e1-6, 2012.

18. Morelli A, Teboul J-L, Maggiore SM, Vieillard-Baron A, Rocco M, Conti G: Effects of levosimendan on right ventricular afterload in patients with acute respiratory distress syndrome: a pilot study. Crit Care Med 34(9):2287-2293, 2006.

19. Boulos M, Astiz ME, Barua RS, Osman M: Impaired mitochondrial function induced by serum from septic shock patients is attenuated by inhibition of nitric oxide synthase and poly(ADP-ribose) synthase. Crit Care Med 31(2):353-358, 2003.
20. Hasslacher J, Bijuklic K, Bertocchi C, Kountchev J, Bellmann R, Dunzendorfer S: Levosimendan inhibits release of reactive oxygen species in polymorphonuclear leukocytes in vitro and in patients with acute heart failure and septic shock: a prospective observational study. Crit Care Lond Engl 15(4):R166, 2011.

21. Torraco A, Carrozzo R, Piemonte F, Pastore A, Tozzi G, Verrigni D: Effects of levosimendan on mitochondrial function in patients with septic shock: a randomized trial. Biochimie 102(1):166-173, 2014.

22. Rosendal L, Blangsted AK, Kristiansen J, Sogaard K, Langberg H, Sjogaard G, Kjaer M: Interstitial muscle lactate, pyruvate and potassium dynamics in the trapezius muscle during repetitive low-force arm movements, measured with microdialysis. Acta Physiol Scand 182(4):379-388, 2004.

23. Fries M, Ince C, Rossaint R, Bleilevens C, Bickenbach J, Rex S, Mik EG: Levosimendan but not norepinephrine improves microvascular oxygenation during experimental septic shock. Crit Care Med 36(6):1886-1891, 2008.

24. Morelli A, Donati A, Ertmer C, Rehberg S, Lange M, Orecchioni A: Levosimendan for resuscitating the microcirculation in patients with septic shock: a randomized controlled study. Crit Care 14(6):R232, 2010.

25. De Backer D, Hollenberg S, Boerma C, Goedhart P, Büchele G, Ospina-Tascon G, Dobbe I, Ince C: How to evaluate the microcirculation: report of a round table conference. Crit Care 11(5):R101-111, 2007.

26. De Backer D, Creteur J, Dubois MJ, Sakr Y, Koch M, Verdant C, Vincent JL: The effects of dobutamine on microcirculatory alterations in patients with septic shock are independent of its systemic effects. Crit Care Med 34(2):403-408, 2006.

27. Hernandez G, Bruhn A, Luengo C, Regueira T, Kattan E, Fuentealba A, Florez J, Castro R, Aquevedo A, Pairumani R, et al.: Effects of dobutamine on systemic, regional and microcirculatory perfusion parameters in septic shock: a randomized, placebo-controlled, double-blind, crossover study. Intensive Care Med 39(8):1435-1443, 2013.

28. Chew MS, Shekar K, Brand BA, Norin C, Barnett AG: Depletion of myocardial glucose is observed during endotoxemic but not hemorrhagic shock in a porcine model. Crit Care 17(4):R164, 2013.

29. Taccone FS, Su F, De Deyne C, Abdellhai A, Pierrakos C, He X, Donadello K, Dewitte O, Vincent JL, De Backer D: Sepsis is associated with altered cerebral microcirculation and tissue hypoxia in experimental peritonitis. Crit Care Med 42(2):e114-e122, 2014.

30. Pojar M, Mand'ák J, Cibícek N, Lonský V, Dominik J, Palicka V, Kubícek J: Peripheral tissue metabolism during off-pump versus on-pump coronary artery bypass graft surgery: the microdialysis study. Eur J Cardiothorac Surg 33(5):899-905, 2008.

31. Michaeli B, Martinez A, Revelly JP, Cayeux MC, Chioléro RL, Tappy L, Berger MM: Effects of endotoxin on lactate metabolism in humans. Crit Care 16(4):R139, 2012.
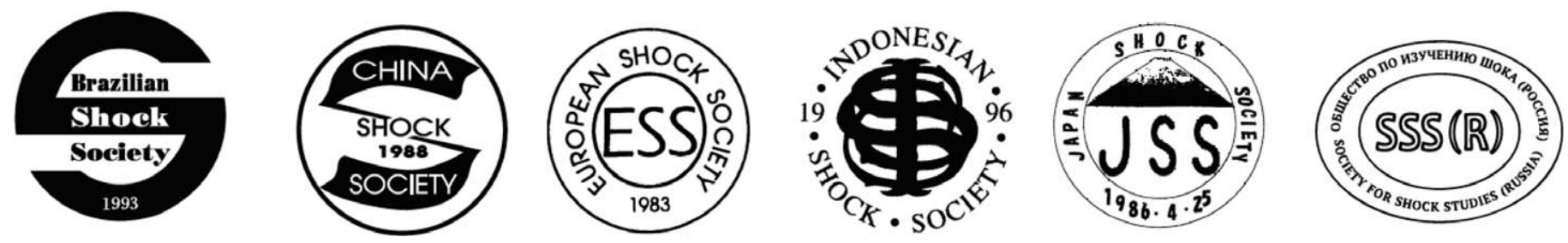